\title{
PENILAIAN RESIKO OPERASIONAL PELAYANAN BONGKAR MUAT KAPAL DI PELABUHAN DILI, TIMOR-LESTE
}

\author{
Minto Basuki ${ }^{1}$, Putu Andhi Indira Kusuma ${ }^{2}$, Zeca Soares ${ }^{3}$ \\ Jurusan Teknik Perkapalan, Institut Teknologi Adhi Tama Surabaya ${ }^{1,2,3)}$, \\ Jl. Arief Rachman Hakim, Surabaya, Jawa Timur, 60117 \\ email: mintobasuki@yahoo.co.id ${ }^{*}$
}

\begin{abstract}
Dili port is the one of port in Timor Leste, that can be used as loading and unloading of goods. The increasing of operations in recent years was could be to the risk. The aim of this study was to analyze the risks involved in the operations of ships loading and unloading in port of Dili. This study was identifying risks, determine risk level, and risk mitigate that affect the processes of loading and unloading. Samples data were the activities loading and unloading that cause risks or accidents reported in 2010 to 2014. The data were analyzed using risk matrix method at probability (likelihood) and impact (consequence) based on AS/NZS 2004 standard. Using this method, there were 22 risk events do to identified. Using the risk matrix, injured due to exposure to the goods or sharp tools, which include a very high risk rating. This mitigate is to provide safety and health training and use to PPE (Personal Protective Equipment) to the labors.
\end{abstract}

Keywords : Ship Operational Risk, Stevedoring, Risk Matrix, Risk Mitigation.

\section{PENDAHULUAN}

Dengan peningkatan perekonomian yang pada beberapa tahun terakhir di negara Timor-Leste, mengakibatkan pertumbuhan pada sistem arus barang ekspor dan impor barang dari dan keluar negeri melalui jalur laut. Pelabuhan Dili berperan sebagai satusatunya daerah penyangga dan distribusi barang di negara Timor - Leste. Peran vital pelabuhan Dili didukung oleh pemerintah Timor - Leste sendiri melalui Kementerian Pekerjaan Umum Transportasi dan Telekomunikasi di bawah koordinasi Direksi Nasional Transportasi Maritim. Ketika Timor - Leste mengimpor maupun mengekspor barang dari negara-negara lain melalui jalur laut, maka proses bongkar muat barang hanya dapat dilakukan di pelabuhan Dili tersebut. Sebab pelabuhan Dili merupakan satu-satunya pelabuhan yang diperuntukan melakukan bongkar muat barang di negara Timor - Leste. Dengan demikian, pertumbuhan kegiatan operasional kapal dan bongkar muat barang di pelabuhan Dili, dari tahun ke tahun semakin meningkat. Peningkatan ini juga membawa dampak tingkat operasional lebih tinggi dibanding dengan beberapa pelabuhan lainnya yang ada di negara Timor - Leste.

Semakin meningkatnya kegiatan operasional kapal dan bongkar muat beberapa tahun terakhir, mengakibatkan banyaknya risiko yang terjadi. Resiko - resiko tersebut berkaitan dengan kegiatan labuh dan sandar kapal, bongkar muat peti kemas, kegiatan perpindahan peti kemas dari dan ke kapal, kegiatan perpindahan peti kemas dari dan ke truck pengangkut, perpindahan peti kemas di lapangan penumpukan, dan proses bongkar muat yang lainnya. Resiko tersebut apabila tidak diantisipasi dengan baik, maka akan memberikan dampak tersendiri bagi pemerintah khususnya dan masyarakat pada umumnya.

Penelitian mengenai Keselamatan dan Kesehatan Kerja (K3) telah dilakukan oleh Prihandono (2010), dengan aspek yang ditinjau antara lain : keselamatan dan kesehatan kerja, biaya dan waktu. Dimana hasil prosentase peluang yang paling besar terjadinya resiko ada dalam Keselamatan dan Kesehatan Kerja (K3). Menurut Saragih dkk (2015), menyatakan bahwa contoh level resiko tinggi dalam penelitiannya adalah pada saat pekerja membuka terpal penutup 
Tabel 1. Hubungan Objektif, KPI dan Cara Mengukur

\begin{tabular}{l|l|l}
\hline \multicolumn{1}{c|}{ Objektif / Tujuan } & \multicolumn{1}{|c|}{ Key Performance Indicator } & \multicolumn{2}{c}{ Cara Mengukur } \\
\hline Mengetahui resiko apa saja yang & Tahap Kapal Berada Di Sepanjang & Sesuai dengan \\
terjadi pada operasional pelayanan & Alur Pelayaran Menuju Kolam & frekuensi jumlah \\
kejadian atau akibat \\
kapal dan bongkar muat barang di & Pelabuhan. & yang terjadi pada \\
pelabuhan Dili sehingga nantinya & Tahap Kapal Berada di Rede atau & tahun 2010 sampai \\
dapat melakukan pencegahan atau & Kolam Pelabuhan. & \\
mengurangi resiko - resiko yang & Tahap Kapal Berada di Dermaga / & \\
terjadi. & Sandar. 2014. \\
& Tahap Kapal Bongkar Muat & \\
& Barang. & \\
& Tahap Bongkar Muat Barang oleh & \\
& Tenaga Kerja Bongkar Muat. & \\
& Tahap Pengangkutan Muatan. & \\
& Tahap Kapal Meninggalkan & \\
& Dermaga. \\
\hline
\end{tabular}

pada kapal serta pekerja memindahkan jalajala berisi barang dari kapal ke dermaga. Setiawan (2015) menyatakan bahwa resiko resiko lingkungan perlu dilakukan, khususnya yang berkaitan dengan proses bongkar muat kapal (kapal tanker). Menurut Hotmauly (2012), resiko dapat dipengaruhi oleh ketidak efektifan kinerja dalam pelaksanaan manajemen resiko, kurangnya kesediaan rambu - rambu keselamatan serta minimnya sumber daya dalam pelaksanaan manajemen resiko tersebut. Basuki dkk (2015), menjelaskan bahwa kejadian risiko yang mempunyai tingkat resiko sangat tinggi adalah resiko terjadinya lost time saat kegiatan truck losing out dan losing in.

\section{METODOLOGI PENELITIAN}

Metodologi penelitian dilakukan dengan urutan sebagai berikut.

a. Penentuan key performance indicator, dalam rangka mengetahui permasalahan dan tujuan dari kontek penelitian.

b. Mengidentifikasi resiko - resiko potensial dengan dasar key performance indicator yaitu kapal mulai masuk alur pelayaran, rede, kapal sandar, kapal bongkar muat, penanganan bongkar muat oleh tenaga bongkar muat, kapal meninggalkan dermaga. resiko - resiko teridentifikasi merupakan data yang terekam pada kurun waktu tahun 2010 sampai tahun 2014. c. Penentuan level probabilitas terjadinya kegagalan dan konsekuensi terjadinya kegagalan menggunakan standar AS/ANZ 2004 pada masing-masing risiko teridentifikasi.

d. Penyusunan matrik resiko.

e. Melakukan proses mitigasi risiko berdasarkan matrik resiko.

\section{PEMBAHASAN DAN HASIL}

3.1 Penentuan Indikator dan Keterukuran

Untuk mencapai obyektif tersebut maka berikut ini adalah beberapa KPI( Key Performance Indicator) yang harus ditentukan sebagai parameter untuk mengidentifikasi resiko - resiko potensial selama kapal dalam alur pelayaran, rede, kapal sandar, kapal bongkar muat, proses bongkar muat oleh tenaga kerja sampai kapal meninggalkan dermaga.

\subsection{Penentuan Resiko Berdasar Kejadian}

Adapun data dan hasil pengamatan dengan pihak yang terkait di pelabuhan Dili, misalnya pihak otoritas atau operator serta para karyawan pelabuhan diperoleh beberapa kejadian yang mengandung unsur risiko sehingga dikategorikan menjadi risk event. Kejadian - kejadian tersebut antara lain : 
Tabel 2. Risk Event

\begin{tabular}{|c|c|c|}
\hline No. & Key Performance Indicator & Risk Event \\
\hline 1. & Kapal berada di sepanjang alur & Gelombang tinggi dan arus deras \\
\hline 2. & $\begin{array}{l}\text { Kapal berada di rede atau kolam } \\
\text { pelabuhan }\end{array}$ & $\begin{array}{l}\text { a. Kapal bertubrukan atau bersenggolan dengan kapal } \\
\text { lain } \\
\text { b. Alur pelayaran yang sempit } \\
\text { c. Gelombang tinggi dan arus deras }\end{array}$ \\
\hline 3. & Kapal berada di dermaga / sandar & $\begin{array}{l}\text { a. Pasang surut air laut } \\
\text { b. Alur pelayaran yang sempit } \\
\text { c. Kapal menabrak dermaga } \\
\text { d. Fasilitas dermaga yang rusak } \\
\text { e. Kapal menabrak atau tertabrak atau bersenggolan oleh } \\
\text { kapal lain }\end{array}$ \\
\hline 4. & Kapal bongkar muat & $\begin{array}{l}\text { a. Tenaga kerja bongkar muat naik ke kapal } \\
\text { b. Loading and unloading containers pada saat di } \\
\text { dermaga } \\
\text { c. Loading and unloading containers pada saat di } \\
\text { container yar atau Lapangan penumpukan } \\
\text { d. Pengaruh cuaca (Hujan dan trik matahari) } \\
\text { e. Kondisi Forklift yang kurang baik }\end{array}$ \\
\hline 5 . & Pada tenaga kerja bongkar muat & $\begin{array}{l}\text { a. Minimnya pengetahuan/skill para tenaga kerja } \\
\text { bongkar muat (Stevdoring) } \\
\text { b. Kondisi para tenaga kerja yang kurang fit } \\
\text { (mengantuk, mabuk) } \\
\text { c. Bekerja tanpa peralatan keselamatan }\end{array}$ \\
\hline 6. & Saat pengangkutan muatan & $\begin{array}{l}\text { a. Kelebihan Muatan ( Overloading) } \\
\text { b. Kondisi alat angkut yang kurang baik } \\
\text { c. Kondisi penggemudi yang kurang baik } \\
\text { a. Pasang surut air laut }\end{array}$ \\
\hline 7. & Kapal meninggalkan dermaga & $\begin{array}{l}\text { b. Alur pelayaran yang sempit } \\
\text { c. Kapal menarik dermaga }\end{array}$ \\
\hline
\end{tabular}

Tabel 3. Level Kemungkinan

\begin{tabular}{|c|c|c|c|}
\hline No. & Variabel Risiko & $\begin{array}{c}\text { Rata - rata } \\
\text { Kemungkinan }\end{array}$ & Level Kemungkinan \\
\hline $\begin{array}{l}1 \\
2 \\
3 \\
4 \\
5 \\
6 \\
7 \\
8 \\
9 \\
10 \\
\\
11 \\
12 \\
13 \\
14\end{array}$ & $\begin{array}{l}\text { Kapal kandas } \\
\text { Kapal patah } \\
\text { Kapal bocor } \\
\text { Kapal larat/hanyut terbawa arus } \\
\text { Kapal bertubrukan atau bersenggolan } \\
\text { Fasilitas dermaga rusak } \\
\text { Tempat sandar kapal semakin sempit } \\
\text { TKBM terpleset, kejatuhan benda di kapal } \\
\text { TKBM terjatuh dari ketinggian saat } \\
\text { berada di atas kontainer } \\
\text { TKBM tertimpa kontainer atau petikemas } \\
\text { saat loading and unloading } \\
\text { TKBM tertabrak side loader } \\
\text { Proses bongkar muat terlambat/tertunda } \\
\text { Muatan jatuh atau tumpah } \\
\text { Kinerja dalam melakukan bongkar muat } \\
\text { tidak efektif dan efisien }\end{array}$ & $\begin{array}{c}0,2 \% \\
0,2 \% \\
0,2 \% \\
0,2 \% \\
23,4 \% \\
5,8 \% \\
4,4 \% \\
4,2 \% \\
2,0 \% \\
0,2 \% \\
0,4 \% \\
38 \% \\
0,6 \% \\
22,2 \%\end{array}$ & $\begin{array}{l}\text { Rare } \\
\text { Rare } \\
\text { Rare } \\
\text { Rare } \\
\text { Almost Certain } \\
\text { Possible } \\
\text { Unlikely } \\
\text { Unlikely } \\
\text { Unlikely } \\
\text { Rare } \\
\text { Rare } \\
\text { Almost Certain } \\
\text { Rare } \\
\text { Almost Certain }\end{array}$ \\
\hline
\end{tabular}




\begin{tabular}{c|l|c|c}
\hline No. & \multicolumn{1}{|c|}{ Variabel Risiko } & $\begin{array}{c}\text { Rata - rata } \\
\text { Kemungkinan }\end{array}$ & Level Kemungkinan \\
\hline 15 & $\begin{array}{l}\text { Jatuh saat melakukan bongkar muat } \\
\text { barang } \\
\text { Kekeliruan dalam mengatur barang- } \\
\text { barang dari kapal ke truck begitu juga } \\
\text { sebaliknya. }\end{array}$ & $11,4 \%$ & Likely \\
17 & $\begin{array}{l}\text { Luka akibat terkena barang-barang/alat } \\
\text { tajam }\end{array}$ & $13,6 \%$ & Unlikely \\
18 & $\begin{array}{l}\text { Truck terbalik } \\
\text { Mengangkut barang dalam jumlah yang }\end{array}$ & $0,6 \%$ & Likely \\
20 & $\begin{array}{l}\text { lebih sedikit } \\
\text { Menabrak tumpukan kontainer di } \\
\text { lapangan penumpukan }\end{array}$ & $\begin{array}{l}\text { Kapal terdampar } \\
\text { Roda pengaman dermaga putus }\end{array}$ & Rare \\
22 & $0,6 \%$ & Possible \\
\end{tabular}

Tabel 4. Level Konsekuensi

\begin{tabular}{|c|c|c|c|}
\hline No. & Variabel Risiko & $\begin{array}{c}\text { Rata - rata } \\
\text { Jumlah Hari } \\
\text { Hilang } \\
\end{array}$ & Level Konsekueni \\
\hline 1 & Kapal kandas & 1 & Insignificant \\
\hline 2 & Kapal patah & 0 & Insignificant \\
\hline 3 & Kapal bocor & 0 & Insignificant \\
\hline 4 & Kapal larat/hanyut terbawa arus & 1 & Insignificant \\
\hline 5 & Kapal bertubrukan atau bersenggolan & 0 & Insignificant \\
\hline 6 & Fasilitas dermaga rusak & 6 & Insignificant \\
\hline 7 & Tempat sandar kapal semakin sempit & 8 & Insignificant \\
\hline 8 & TKBM terpleset, kejatuhan benda di kapal & 0 & Insignificant \\
\hline 9 & $\begin{array}{l}\text { TKBM terjatuh dari ketinggian saat berada } \\
\text { di atas kontainer }\end{array}$ & 25 & Insignificant \\
\hline 10 & $\begin{array}{l}\text { TKBM tertimpa kontainer atau petikemas } \\
\text { saat loading and unloading }\end{array}$ & 1 & Insignificant \\
\hline 11 & TKBM tertabrak side loader & 8 & Insignificant \\
\hline 12 & Proses bongkar muat terlambat/tertunda & 3 & Insignificant \\
\hline 13 & Muatan jatuh atau tumpah & 2 & Insignificant \\
\hline 14 & $\begin{array}{l}\text { Kinerja dalam melakukan bongkar muat } \\
\text { tidak efektif dan efisien }\end{array}$ & 45 & Moderate \\
\hline 15 & Jatuh saat melakukan bongkar muat barang & 40 & Moderate \\
\hline 16 & $\begin{array}{l}\text { Kekeliruan dalam mengatur barang-barang } \\
\text { dari kapal ke truck begitu juga sebaliknya. }\end{array}$ & 14 & Minor \\
\hline 17 & $\begin{array}{l}\text { Luka akibat terkena barang-barang/alat } \\
\text { tajam }\end{array}$ & 133 & Catastrophic \\
\hline 18 & Truck terbalik & 2 & Insignificant \\
\hline 19 & $\begin{array}{l}\text { Mengangkut barang dalam jumlah yang } \\
\text { lebih sedikit }\end{array}$ & 2 & Insignificant \\
\hline 20 & $\begin{array}{l}\text { Menabrak tumpukan kontainer di lapangan } \\
\text { penumpukan }\end{array}$ & 0 & Insignificant \\
\hline 21 & Kapal terdampar & 2 & Insignificant \\
\hline 22 & Roda pengaman dermaga putus & 0 & Insignificant \\
\hline
\end{tabular}




\subsection{Penentuan Level Kemungkinan dan Level Konsekuensi}

Level kemungkinan dapat dilihat seperti tabel diatas (AS/ANZ, 2004) dan Level konsekuensi dapat dilihat seperti pada tabel diatas (AS/ANZ, 2004).

\subsection{Matrik Resiko}

Level kemungkinan dan level konsekuensi tersebut pada paragraf 3.3 dimasukan dalam matrik resiko seperti gambar 1 . Nomor yang tertera dalam matrik resiko adalah nomor variabel resiko.

\subsection{Mitigasi Resiko}

Setelah didapatkan indek resiko dari matrik resiko, kejadian resiko yang memiliki rating resiko sangat tinggi dan tinggi, perlu dilakukan proses mitigasi.

Mitigasi resiko yaitu menggeser peringkat resiko ke satu tingkat dibawahnya pada sumbu dampak atau konsekuensi. Proses mitigasi resiko dilakukan dengan kegiatan seperti tabel 5.

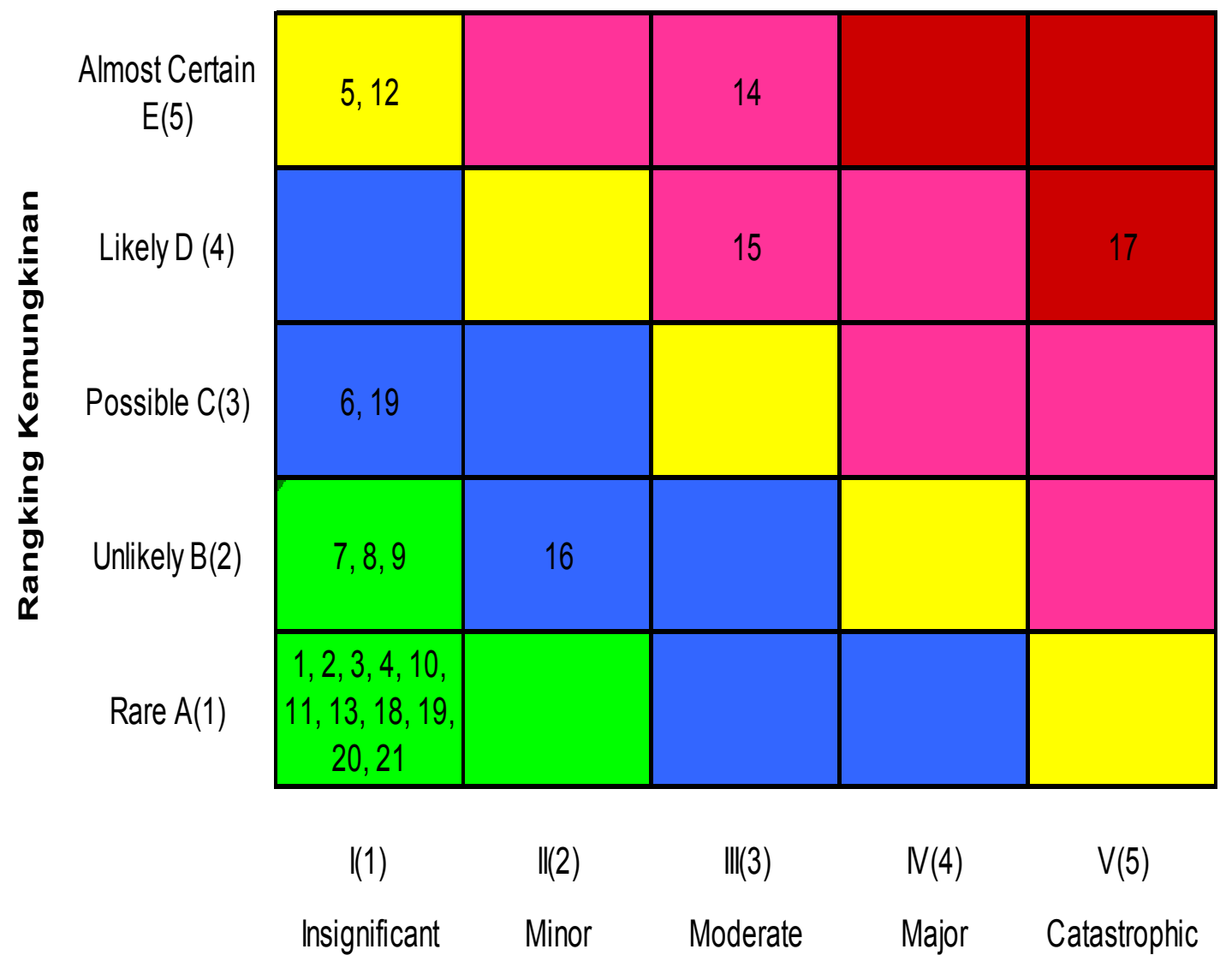

\section{Rangking Dampak/Konsekuensi}

\begin{tabular}{|c|c|}
\hline Tingkat Eksposur/ Level & Indeks Risiko \\
\hline Sangat Tinggi (E) & $9 \mathrm{~s} / \mathrm{d} 10$ \\
\hline Tinggi $(\mathrm{T})$ & $7 \mathrm{~s} / \mathrm{d} 8$ \\
\hline Menengah $(\mathrm{M})$ & 6 \\
\hline Rendah $(\mathrm{R})$ & $4 \mathrm{~s} / \mathrm{d} 5$ \\
\hline Sangat Rendah $(\mathrm{S})$ & $2 \mathrm{~s} / \mathrm{d} 3$ \\
\hline
\end{tabular}

Gambar 1. Matrik Resiko. 
Tabel 5. Mitigasi Resiko

\begin{tabular}{|c|c|c|c|}
\hline No. & Kejadian Risiko & Risk Rating & Mitigasi \\
\hline 1 & $\begin{array}{l}\text { Luka akibat terkena } \\
\text { barang - barang / alat } \\
\text { tajam. }\end{array}$ & Sangat Tinggi & $\begin{array}{l}\text { Mewajibkan pemakaian APD (Alat Pengaman } \\
\text { Diri) bagi para pekerja. } \\
\text { Memberikan pelatihan tentang keselamatan } \\
\text { dan kesehatan kerja (K3) setidaknya enam } \\
\text { bulan sekali. } \\
\text { Memberikan sanksi yang tegas bagi yang } \\
\text { melanggar aturan keselamatan sesuai dengan } \\
\text { perundangan. }\end{array}$ \\
\hline 2 & $\begin{array}{l}\text { Kinerja dalam } \\
\text { melakukan bongkar } \\
\text { muat tidak efektif dan } \\
\text { efisien. }\end{array}$ & Tinggi & $\begin{array}{l}>\text { Menambah peralatan bongkar muat. } \\
>\text { Menyusun dan menerapkan SOP untuk } \\
\text { kegiatan bongkar muat. } \\
>\text { Peningkatan sistim insentif bagi pekerja } \\
\text { bongkar muat. } \\
>\text { Peremajaan fasilitas pendukung bongkar } \\
\text { muat. }\end{array}$ \\
\hline 3 & $\begin{array}{l}\text { Jatuh saat melakukan } \\
\text { bongkar muat barang. }\end{array}$ & Tinggi & $\begin{array}{l}\text { Mewajibkan pemakaian APD (Alat Pengaman } \\
\text { Diri) bagi para pekerja. } \\
\text { Pemasangan jaring pengaman disekitar area } \\
\text { bongkar muat. } \\
\text { Memberikan pelatihan tentang keselamatan } \\
\text { dan kesehatan kerja (K3) setidaknya enam } \\
\text { bulan sekali. }\end{array}$ \\
\hline
\end{tabular}

\section{KESIMPULAN}

1. Beberapa kejadian resiko yang teridentifikasi ada 22 macam, sesuai dengan key performance indicator yang telah ditetapkan, dan dilakukan proses penilaian resiko.

2. Dari kejadian - kejadian tersebut yang memiliki risk rating sangat tinggi diantaranya adalah luka akibat terkena barang - barang / alat tajam. Risk rating tinggi diantaranya adalah Kinerja dalam melakukan bongkar muat tidak efektif dan efisien, Jatuh saat melakukan bongkar muat barang.
3. Mitigasi (menggeser peringkat risiko menjadi satu peringkat dibawahnya) yang perlu dilakukan pada kejadian resiko yang memiliki risk rating sangat tinggi dan tinggi. Risk rating sangat tinggi yaitu luka akibat terkena barang - barang / alat tajam. Risk rating tinggi yaitu kinerja dalam melakukan bongkar muat tidak efektif dan efisien dan jatuh saat melakukan bongkar muat barang. 


\section{DAFTAR PUSTAKA}

Australia Standard New Zealand Standard (AS / NZS 4360;2004).

Basuki, M., Susanto, R., Herianto, H, Analisis Risiko Kegiatan Bongkar Muat Sebagai Komponen Dwelling Time Di Pelabuhan, Prosiding SNTEKPAN III, Tahun 2015, ITATS, 2015.

Hotmauly, Gambaran Pelaksanaan Manajemen Risiko Keselamatan Terminal Peti Kemas Koja, Tanjung Priuk Jakarta Periode Juni 2012, Skripsi, Departemen Keselamatan dan Kesehatan Kerja, FKM, UI, 2012.

Prihandono, E, Analisa Risiko Kegiatan Operasional Bongkar Muat Petikemas Di Dermaga Nilam Timur Multipurpose Pelabuhan Tanjung Perak Surabaya, Tesis, Magister Manajemen Teknik, MMT, ITS, 2010.

Setiawan, A, Tinjauan Perlindungan Lingkungan Akibat Operasional Kapal di Pelabuhan Tanjung Perak Surabaya, Skripsi, Jurusan Teknik Perkapalan, FTMK, ITATS., 2015.

Saragih, W.L., Mahyuni, E.L., dan Lubis, A.M, Penilaian Risiko Pada Tenaga Kerja Bongkar Muat di Pelabuhan Teluk Nibung Tanjung Balai Asahan, Medan Tahun 2015, Skripsi, Departemen Keselamatan dan Kesehatan Kerja, FKM, USU, 2015. 